\title{
Contribuição da fixação biológica de nitrogênio, fertilizante nitrogenado e nitrogênio do solo no desenvolvimento de feijão e caupi
}

\author{
Marciano de Medeiros Pereira Brito ( $\left.{ }^{1}\right)$; Takashi Muraoka ( $\left.{ }^{2}\right)$; Edson Cabral da Silva $\left(2^{*}\right)$ \\ (') Centro de Energia Nuclear na Agricultura, Universidade de São Paulo (CENA/USP), Divisão de Produtividade Agroindustrial e \\ Alimentos, Caixa Postal 96, 13416-000 Piracicaba (SP).E-mail: marcianobrito@hotmail.com; muraoka@cena.usp.br; \\ ecsilva@cena.usp.br (*) Autor correspondente.
}

Recebido: 23/out./2009; Aceito: 2/ago./2010

\begin{abstract}
Resumo
A fixação biológica do nitrogênio (FBN) constitui-se em uma valiosa fonte deste nutriente para o feijão comum e, sobretudo, para o feijão-caupi, tendo sua magnitude influenciada pela disponibilidade de $\mathrm{N}$ mineral na solução do solo. Os objetivos deste trabalho foram: avaliar os efeitos de doses de nitrogênio, na forma de uréia, sobre a fixação simbiótica de $\mathrm{N}_{2}$ em feijão comum e caupi, pela técnica isotópica, e quantificar as contribuições relativas das fontes $\mathrm{N}_{2}$-fixação simbiótica, $\mathrm{N}$-solo e $\mathrm{N}$ uréia no desenvolvimento do feijão comum e caupi, usando como controle a soja não nodulante. O estudo foi desenvolvido em casa de vegetação, utilizando-se vasos com 5 kg de terra, coletada de Latossolo Vermelho-Amarelo distrófico. O delineamento experimental foi em blocos casualizados em esquema fatorial $5 \times 3 \times 2$ e três repetições. Os tratamentos compreenderam cinco doses de N, na forma de uréia: 2, 15, 30, 45 e $60 \mathrm{mg} \mathrm{kg}^{-1}$ de N; três épocas de amostragens de plantas: 23,40 e 76 dias após a semeadura (DAS) e duas culturas: feijão comum e feijão caupi. A FBN decresceu com o incremento da dose de $\mathrm{N}$, variando de $81,5 \%$ a 55,6\% para o caupi e de $71,9 \%$ a 55,1\% para o feijão comum. A FBN em caupi submetido à inoculação pode substituir totalmente a adubação nitrogenada, inclusive a dose de arranque. A absorção do $\mathrm{N}$ do solo não é influenciada pela dose de fertilizante nitrogenado. O aproveitamento do N do fertilizante, aos 76 DAS, foi, em média, de 60,7\% pelo feijão comum e 57,1\% pelo caupi. O feijão comum necessita de dose de arranque (40 kg ha-1 de N) para a obtenção de produtividade economicamente aceitável.
\end{abstract}

Palavras-chave: Vigna unguiculata, Phaseolus vulgaris, ${ }^{15} \mathrm{~N}$, leguminosa, dose de nitrogênio.

\section{Contribuition of nitrogen from biological nitrogen fixation, nitrogen fertilizer and soil nitrogen on the growth of the common bean and cowpea}

\begin{abstract}
Biological nitrogen fixation (BNF) constitutes a valuable source of this nutrient for the common bean Phaseolus vulgaris $L$. and cowpea Vigna unguiculata (L.) Walp., being its avaibility affected by mineral $\mathrm{N}$ in the soil solution. The objectives of this work were to evaluate the effects of nitrogen rate, as urea, on symbiotic fixation of $\mathrm{N}_{2}$ in common bean and cowpea plants, using the isotopic technique, and quantifying the relative contributions of $\mathrm{N}$ sources symbiotic $\mathrm{N}_{2}$ fixation, soil native nitrogen and urea $\mathrm{N}$ on the growth of the common bean and cowpea. Non nodulating soybean plants were used as standard. The research was carried out in greenhouse, using pots with $5 \mathrm{~kg}$ of soil from a Typic Haplustox (Dystrophic Red Yellow Latosol). The experimental design was completely randomized blocks, with 30 treatments and three replications, arranged in $5 \times 3 \times 2$ factorial outline. The treatments consisted of five $\mathrm{N}$ rates: 2, 15, 30, 45 and $60 \mathrm{mg} \mathrm{N} \mathrm{kg}^{-1}$ soil; three sampling times: 23,40 and 76 days after sowing (DAS) and two crops: common bean and cowpea. The BNF decreased with increase $\mathrm{N}$ rates, varying from $81.5 \%$ to $55.6 \%$ for cowpea, and from $71.9 \%$ to $55.1 \%$ for common bean. The symbiotic $\mathrm{N}_{2}$ fixation in cowpea can substitute totally the nitrogen fertilization. The nitrogen absorption from soil is not affected by nitrogen fertilizer rate. The $\mathrm{N}$ recovery from fertilizer at 76 DAS was of $60.7 \%$ by common bean, and $57.1 \%$ by cowpea. The symbiotic association in common bean needs the application of a starting dose $\left(40 \mathrm{~kg} \mathrm{~N} \mathrm{ha}^{-1}\right)$ for economically acceptable yields.
\end{abstract}

Key words: Vigna unguiculata, Phaseolus vulgaris, nitrogen-15, legume, N rate. 


\section{INTRODUÇÃO}

O feijão-caupi é uma espécie com ampla distribuição mundial, principalmente nas regiốes tropicais, em virtude de terem condiçôes edafoclimáticas semelhantes às do seu provável berço de origem, a África. Segundo a FaO (2004), estima-se que em 2003 foram cultivados no mundo cerca de 9,82 milhões de hectares de feijão-caupi. No Brasil, estima-se que é cultivado em torno de 1,5 milhão de hectares de feijâo-caupi, com produtividade média de aproximadamente $300 \mathrm{~kg} \mathrm{ha}^{-1}$ (EMbrapa Semi-Árido, 2008). Dentre os vários fatores que contribuem para a baixa produtividade média dessas espécies, destaca-se o manejo da fertilidade do solo, particularmente pelo insuficiente suprimento de nitrogênio (Hungria et al., 1991; Martins et al., 2003). Estima-se que em $40 \%$ da área cultivada com feijoeiro na América Latina e em $60 \%$ das áreas na África e no Oriente Médio ocorram deficiência de N (CIAT, 1990).

O sucesso na formação de uma simbiose funcional é dependente de muitos fatores não sequenciais, tais como: físicos, ambientais, nutricionais e biológicos (Hungria et al., 1991) e, também, de fatores relacionados à planta (cultivar) e à estirpe, bem como pela interação entre estes (Hungria e Vargas, i997; Soares et al., 2006a,b). A capacidade de FBN do feijoeiro parece não ser tão eficiente quanto à do caupi (Martins et al., 2003; Xavier et al., 2007) e à da cultura da soja (Hungria et al., 1991, Mendes et al., 2008). Para a obtenção de rendimentos econômicos, geralmente, é essencial a suplementação nitrogenada, principalmente até que a nodulação esteja plenamente estabelecida (Oliveira et al., 2003). No entanto, é necessária uma dose de $\mathrm{N}$ que proporcione bom desenvolvimento da planta, mas que não venha prejudicar a FBN.

Segundo Oliveira e Thung (1988), embora seja necessário conhecer a cultivar, as condições de desenvolvimento da cultura do feijão comum, para a produção de $1500 \mathrm{~kg} \mathrm{ha}^{-1}$ de grãos, necessita-se aproximadamente de $46 \mathrm{~kg}$ de $\mathrm{N}$. Os autores recomendam a aplicação de $\mathrm{N}$ na semeadura e em cobertura, na fase de 25 a 35 dias após a emergência (DAE). A espécie de rizóbio recomendada para produção de inoculantes para a cultura do feijoeiro é Rhizobium tropici (Martinez-Romero et al., 1991), compreendendo as estirpes comerciais SEMIA 4077 (CIAT 899) e SEMIA 4080 (PRF 81). Pelegrin et al. (2009) verificaram que a adubação com $20 \mathrm{~kg} \mathrm{ha}^{-1}$ de N, acrescida de inoculante com a estirpe de Rhizobium tropici CIAT 899 possibilitou a obtenção de rendimento de grãos na cultura de feijoeiro equivalente à aplicação de até $160 \mathrm{~kg} \mathrm{ha}^{-1} \mathrm{de} \mathrm{N}$.

Martins et al. (2003) relataram que a inoculação de rizóbio em caupi, em área de sequeiro, pode aumentar a produtividade em até $35 \%$, equivalente à aplicação de 50 $\mathrm{kg} \mathrm{ha}^{-1}$ de $\mathrm{N}$ mineral. Por sua vez, SoAres et al. (2006a) verificaram que a inoculação em campo, com as estirpes UFLA 03-84 e INPA 03-11B, contribuiu para o aumento no rendimento de grãos, semelhantemente ao tratamento testemunha que recebeu $70 \mathrm{~kg} \mathrm{ha}^{-1}$ de $\mathrm{N}$, e superior ao da estirpe BR 2001. Esta estirpe, embora não seja mais recomendada como inoculante, estabelece simbiose eficiente com o caupi (Martins et al. 2003; Xaviér et al., 2007).

Conforme Oliveira e Dantas (1988) o caupi depende do nitrogênio da semente e do $\mathrm{N}$ do solo até os 20 DAE e, havendo condiçóes de solo e da planta para uma simbiose efetiva, é dispensada a adubação mineral nitrogenada. A partir dos $25 \mathrm{DAE}$, a necessidade da cultura em $\mathrm{N}$ é suprida pela FBN, estendendo-se até a floração, que normalmente ocorre entre 45 e 55 DAE, para cultivares de porte determinado, e entre 75 e 90 dias para os de porte indeterminado.

Segundo Sprent e Sprent (1990), é necessário que haja disponibilidade de $\mathrm{N}$ combinado para o crescimento do rizóbio até o início da fixação de $\mathrm{N}_{2}$ Em estudos realizados por Summerfield et al. (1977) e HuXley (1980), constatou-se que baixas doses de $\mathrm{N}$ combinado beneficiam a nodulação, fixação e produção do caupi. Já Alfaia (1997) não obteve resposta do caupi à aplicação de fertilizante nitrogenado, na forma de uréia ou sulfato de amônio, na dose de $30 \mathrm{~kg} \mathrm{ha}^{-1}$ de N. Eaglesham et al. (1983), em estudos utilizando ${ }^{15} \mathrm{~N}$ para avaliar o efeito de três formas de $\mathrm{N}$ combinado $\left(\mathrm{KNO}_{3}, \mathrm{NH}_{4} \mathrm{NO}_{3}\right.$ e uréia) em duas variedades de caupi e uma de soja, concluíram que a aplicação de $\mathrm{N}$ nas dose de 30 a $180 \mathrm{mg}$ planta $^{-1}$ promoveu efeito sinérgico na fixação de $\mathrm{N}_{2}$.

O objetivo deste trabalho foi avaliar os efeitos de doses de nitrogênio, na forma de uréia, sobre a fixação simbiótica de $\mathrm{N}_{2}$ em feijão comum e caupi ao longo do ciclo, pela técnica isotópica, e quantificar as contribuiçóes relativas das fontes $\mathrm{N}_{2}$-fixaçáo simbiótica, $\mathrm{N}$-solo e $\mathrm{N}$-uréia no desenvolvimento do feijão comum e caupi.

\section{MATERIAL E MÉTODOS}

O estudo foi desenvolvido em casa de vegetação, em Piracicaba (SP), utilizando-se Latossolo Vermelho-Amarelo distrófico, textura média, coletado na região. $\mathrm{O}$ solo foi coletado na camada de $0-20 \mathrm{~cm}$ de profundidade, seco ao ar, destorroado, homogenizado e passado em peneira de $4 \mathrm{~mm}$ de abertura, e em seguida, acondicionados $5 \mathrm{~kg}$ de solo por vaso. A análise química antes da implantação do experimento resultou nos seguintes valores: $\mathrm{pH}\left(\mathrm{CaCl}_{2}\right)$ 5,2; M.O. 20,5 $\mathrm{g} \mathrm{dm}^{-3}$; P (resina) 6,0 $\mathrm{mg} \mathrm{dm}^{-3}$; Ca 9,3 $\mathrm{mmol}_{\mathrm{c}} \mathrm{dm}^{-3} ; \mathrm{Mg} 2,4 \mathrm{mmol}_{\mathrm{c}} \mathrm{dm}^{-3} ; \mathrm{K} \mathrm{0,5} \mathrm{mmol}_{\mathrm{c}} \mathrm{dm}^{-3}$; $\mathrm{H}+\mathrm{Al} 43,0 \mathrm{mmol}_{\mathrm{c}} \mathrm{dm}^{-3}$; SB 12,2 $\mathrm{mmol}_{\mathrm{c}} \mathrm{dm}^{-3}$; CTC 55,0 $\mathrm{mmol}_{\mathrm{c}} \mathrm{dm}^{-3}$ saturação por bases 22,1\%; Zn (DTPA) 3,4 $\mathrm{mg} \mathrm{dm}{ }^{-3}$; Cu (DTPA) 0,6 $\mathrm{mg} \mathrm{dm}^{-3}$; Mn (DTPA) 4,2 $\mathrm{mg}$ $\mathrm{dm}^{-3}$; Fe (DTPA) $58,0 \mathrm{mg} \mathrm{dm}^{-3}$. A análise granulométrica proporcionou os seguintes valores $\left(\mathrm{g} \mathrm{kg}^{-1}\right)$ : areia, 720 ; silte 
60; e argila 220, determinadas pelo método da pipeta, conforme metodologia descrita em DAY (1965).

A correção do solo foi realizada um mês antes da semeadura, na dose de 2,04 $\mathrm{Mg} \mathrm{ha}^{-1}$ de calcário dolomítico (PRNT 100\%), considerando-se os resultados da análise do solo e a recomendação da Associaçáo Nacional para Difusão de Corretivos Agrícolas (1986). O solo foi mantido umedecido a $60 \%$ da capacidade de campo, com a finalidade de mais prontamente elevar o $\mathrm{pH}$. No décimo sexto dia após a correção do solo, foram aplicados 100 $\mathrm{mg} \mathrm{kg}^{-1}$ de P e $50 \mathrm{mg} \mathrm{kg}^{-1}$ de $\mathrm{K}$, na forma de superfosfato simples e cloreto de potássio, respectivamente. Foram aplicados também micronutrientes, na forma de solução $\left(\mathrm{MnCl}_{2} 1,81 \mathrm{~g} \mathrm{~L}^{-1} ; \mathrm{Zn} \mathrm{SO}_{4} 0,22 \mathrm{~g} \mathrm{~L}^{-1} ; \mathrm{CuSO}_{4} 0,08 \mathrm{~g} \mathrm{~L}^{-1}\right.$;

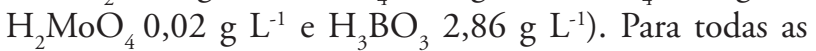
soluções, usaram-se água destilada e sais p.a.

O delineamento experimental foi em blocos casualizados em esquema fatorial $5 \times 3 \times 2$ e três repetiçôes. Os tratamentos compreenderam cinco doses de $\mathrm{N}$, na forma de uréia: 2, 15, 30, 45 e $60 \mathrm{mg} \mathrm{kg}^{-1}$ de $\mathrm{N}$; três épocas de amostragens de plantas: 23, 40 e 76 dias após a semeadura (DAS) e duas culturas: feijão comum e feijão caupi. Como planta controle da fixação biológica de $\mathrm{N}_{2}$, foi utilizada a soja náo nodulante. As doses de 2, 15, 30, 45 e $60 \mathrm{mg} \mathrm{kg}^{-1} \mathrm{de} \mathrm{N}$ de solo equivaleram, respectivamente, à aplicação de 5,3; 40, 80, 120 e $160 \mathrm{~kg} \mathrm{ha}^{-1}$ de N. O enriquecimento isotópico utilizado foi de $30 \%$ e $10 \%$ de átomos de ${ }^{15} \mathrm{~N}$ em excesso, respectivamente, para as doses de 2 e $15 \mathrm{mg} \mathrm{kg}^{-1}$ de N. Para as demais doses de $\mathrm{N}$, utilizou-se um enriquecimento de 4,991\% de átomos de ${ }^{15} \mathrm{~N}$ em excesso. Para facilitar a aplicação uniforme, o fertilizante nitrogenado foi diluído em $50 \mathrm{ml}$ de água destilada e aplicado com auxílio de uma pipeta.

$\mathrm{Na}$ semeadura do feijāo comum (cultivar Carioca), do caupi (cultivar CNC x 284-4E) e da soja não nodulante (D-71-9331), utilizaram-se seis sementes por vaso, com posterior desbaste deixando-se três plantas. As regas foram realizadas diariamente com água destilada, procurandose manter $80 \%$ da capacidade de campo. Para estimativa da reposição da água, determinou-se a curva característica do solo e realizaram-se pesagens para estimar a quantidade evapotranspirada. As sementes do feijão comum foram incubadas, antes da semeadura, com estirpes de Rhizobium CIAT 899. Para o caupi, utilizou-se a estirpe de Bradyrhizobium BR 2001. Detalhamentos sobre a origem (sistema de uso da terra, município, estado e país) e características culturais das estirpes de rizóbios usadas podem ser obtidos em SoAres et al. (2006a) para o caupi e SoARes et al. (2006b) para o feijoeiro.

A colheita das plantas foi realizada por amostragens ao longo do ciclo das culturas (23, 40 e 76 DAS). O material colhido de cada vaso (folhas + ramos + pecíolos + pedúnculos e vagens) foi seco em estufa de circulação de ar forçado a $65^{\circ} \mathrm{C}$ até atingir massa constante, determinando-se a matéria seca por planta. Em seguida, o material foi misturado, moído em moinho tipo Wiley com peneira de 40 mesh $(0,42 \mathrm{~mm})$, homogeneizado e deste retiradas amostras para análises de $\mathrm{N}$ total e concentração isotópica.

A atividade da enzima nitrogenase foi medida indiretamente pelo método da atividade de redução do acetileno (ARA) (Hardy et al., 1968). Após a coleta, as raízes foram colocadas em frascos de vidros de $1000 \mathrm{~mL}$ e, em seguida, fechadas hermeticamente. Retiraram-se previamente 10\% da atmosfera do vidro sendo injetado $10 \%$ de $\mathrm{C}_{2} \mathrm{H}_{2}$. Após 30 minutos, retirou-se amostra com seringas plásticas e injetou-se $0,5 \mathrm{~cm}^{3}$ em cromatógrafo de gás tipo BECKMAN modelo GC-65, usando-se detector de ionização de chama de $\mathrm{H}_{2}$ a $125^{\circ} \mathrm{C}$ e coluna contendo Poropak $\mathrm{N}$ de 80 a 100 mesh a $50{ }^{\circ} \mathrm{C}$, conforme metodologia descrita em Saito (1980). Preparou-se padrão de $500 \mathrm{mg} \mathrm{L}^{-1} \mathrm{de}$ $\mathrm{C}_{2} \mathrm{H}_{2}$ para determinação do controle, vidros sem raízes e com injeçáo de $\mathrm{C}_{2} \mathrm{H}_{2}$.

$\mathrm{O} \mathrm{N}$ total foi determinado pelo método de Kjeldahl descrito por Bremner e Mulvaney (1982). Para as análises da composição isotópica de $\mathrm{N}$, as amostras foram processadas de acordo com o método de RitTenberg (1946); partindo do destilado final obtido na análise da porcentagem de $\mathrm{N}$ total (Kjeldahl) que foi novamente acidificado com $\mathrm{H}_{2} \mathrm{SO}_{4} 0,05 \mathrm{~mol} / \mathrm{L}$ e concentrado por evaporação, $\mathrm{o} \mathrm{N}-\mathrm{NH}_{4}^{+}$foi convertido a $\mathrm{N}_{2}$ por oxidação com hipobrometo de lítio (LiOBr) (Porter e O’Deen, 1977). As análises da composição isotópica de nitrogênio nas amostras foram determinadas em espectrômetro de massa ATLAS VARIAN MAT modelo CH-4. As avaliações seguiram a seguinte sequência de cálculos:

a) Determinação da atividade da nitrogenase

$$
\begin{aligned}
& \mathrm{C}_{2} \mathrm{H}_{4}=(\text { nmoleslh }=\text { kxk' } x \text { (volume do frasco) } x \\
& \frac{1}{\text { (volume injetado }\left(\mathrm{cm}^{3}\right)} \times \frac{1}{(\text { tempo de incubaçáo }(\mathrm{h}))} \\
& \mathrm{K}=\frac{11,16 \text { moles de } \mathrm{C}_{2} \mathrm{H}_{4} \mathrm{em} 0,5 \mathrm{~cm}^{3} \text { do padráo (C.N.T.P.) }}{\mathrm{H} \times \mathrm{AxR}}
\end{aligned}
$$

Sendo: $\mathrm{H}=$ altura do pico do padrão; $\mathrm{A}=$ atenuação da leitura; $\mathrm{R}$ = range; $\mathrm{K}^{\prime}$ = altura do pico da amostra $(\mathrm{mm})$ $\mathrm{x}$ atenuaçáo $\mathrm{x}$ range

Os resultados foram apresentados em mmoles $\mathrm{C}_{2} \mathrm{H}_{4}$ planta hora ${ }^{-1}$ ou $\mu \mathrm{mol} \mathrm{C}_{2} \mathrm{H}_{4}$ planta hora ${ }^{-1}$, a partir dos valores obtidos pela altura do pico em relaçáo ao padrão de $500 \mathrm{mg} \mathrm{kg}^{-1}$ de etileno.

b) Quantidade de nitrogênio total acumulada (QNT, mg planta $^{-1}$ )

$$
\mathrm{QNT}=\frac{\mathrm{RMS} \times \mathrm{N}}{1000}
$$


Sendo: $\mathrm{RMS}=$ rendimento de matéria seca $\left(\mathrm{g}_{\mathrm{planta}}{ }^{-1}\right) ; \mathrm{N}$ $=$ teor de nitrogênio na planta $\left(\mathrm{g} \mathrm{kg}^{-1}\right)$

c) Percentagem de nitrogênio na planta (caule + ramos + folhas + pedúnculos e vagens) proveniente do fertilizante (NPPF, \%)

$\% \mathrm{NPPF}=\frac{\% \text { Átomos de }{ }^{15} \mathrm{~N} \text { em excesso na planta }}{\% \text { Átomos de }{ }^{15} \mathrm{~N} \text { em excesso no fertilizante }} \times 100$

d) Porcentagem de nitrogênio na planta (caule + ramos + folhas + pedúnculos e vagens) proveniente da fixação biológica no feijão caupi e no feijāo comum (NPPFB, $\%)$

$\% \mathrm{NPPFB}=\left(1-\frac{\% \text { Átomos de }{ }^{15} \mathrm{~N} \text { em excesso no feijäo ou caipi }}{\% \text { Átomos de }{ }^{15} \mathrm{~N} \text { em excesso na planta controle }}\right.$

e) Quantidade de nitrogênio proveniente da fixação biológica (QNPPFB, mg planta-1 $)$

$\mathrm{QNPPFBN}=\frac{\% \mathrm{NPPFBN}}{100} \times Q N T$

f) Quantidade de nitrogênio proveniente do solo (QNPPS, mg planta ${ }^{-1}$ )

$$
\mathrm{QNPPS}=Q N T-Q N P P F-Q N P P F B N
$$

g) Aproveitamento do $\mathrm{N}$ do fertilizante (AP, \%), em relação à quantidade de $\mathrm{N}$ aplicado como fertilizante (QNA)

$A P=\frac{Q N P P F}{Q N A} \times 100$

Os dados foram submetidos à análise de variância $\mathrm{e}$, quando detectados efeitos significativos pelo teste F, a 5\% de probabilidade, foram ajustadas equações de regressão. Testou-se à significância dos modelos linear e quadrático, tendo sido escolhida a equação significativa com maior grau. As análises estatísticas foram realizadas com o programa estatístico SAS 8.02 (SAS Institute, 2001).

\section{RESULTADOS E DISCUSSÃO}

As doses de nitrogênio influenciaram a produtividade de matéria seca de parte aérea (MSPA) do feijão comum e do caupi. No entanto, para ambas as espécies, ocorreu discreto aumento MSPA até 23 DAS, moderado até 40 DAS, e acentuado incremento na MSPA de 40 a 76 DAS, tendo alcançado o pico máximo nesta época (Figura 1a,b). O feijão iniciou a emissão de botôes florais aos 40 DAS, atingindo a plena floração aos 50 DAS e, aos 76 DAS, as vagens estavam bem formadas e a planta em estádio de fim de ciclo, o que forçou também a coleta das demais culturas (caupi e soja não nodulante), pois é exigência do método da diluição isotópica (Boddey et al., 1983; Hardarson e Danso, 1990; Alves et al., 2005). O caupi, aos 76 DAS, estava em fase de enchimento das vagens, com sementes mal formadas, portanto, para todas as espécies, foi quantificado e considerado o $\mathrm{N}$ da parte aérea inteira (caule + ramos + folhas + pedúnculos e vagens).

Comparando-se, separadamente, cada espécie dentro de cada época, observa-se que as doses crescentes de $\mathrm{N}$, aos 23 e 40 DAS (Figura 1a,b), proporcionaram produção de MSPA semelhantes.

Para o feijão comum, aos 76 DAS, também não houve diferença significativa entre os tratamentos a partir da dose de $15 \mathrm{mg} \mathrm{kg}^{-1}$ de $\mathrm{N}$, indicando que nestes tratamentos somente a FBN supriu as exigências da planta. Para o caupi, aos 76 DAS, o efeito das doses de $\mathrm{N}$ foi menor que para o feijāo comum, sem diferença significativa na produção de MSPA, inclusive entre os tratamentos nos quais não foi aplicado $\mathrm{N}$ e naqueles que receberam 60 $m g \mathrm{~kg}^{-1}$ de $\mathrm{N}$, sugerindo alta FBN por esta espécie.

Quanto à quantidade de nitrogênio total acumulada (QNT) pelo caupi e pelo feijão, aos 76 DAS, houve um ganho líquido de aproximadamente 3,5 vezes na QNT em relação à época anterior (40 DAS) (Figura 2a,b). Esse aumento, provavelmente, foi devido à maior atividade simbiótica no fim do ciclo da cultura, a exemplo do verificado em outros estudos (Franco et al., 2002; Martins et al., 2003). Para o feijão, aos 23 e aos 40 DAS, os dados ajustaram-se ao modelo linear e, para o caupi, aos 40 DAS, ao modelo quadrático. $\mathrm{O}$ incremento na dose de $\mathrm{N}$ não influenciou a QNT na parte aérea do caupi, aos 23 e 76 DAS.

Considerando-se as doses de $\mathrm{N}$ aplicadas, aos $76 \mathrm{DAS}$, tanto o caupi como o feijão acumularam maior quantidade de $\mathrm{N}$ do que a soja não nodulante. Tal fato, em parte, se deve a serem espécies distintas; porém, sugere-se que houve efeito sinérgico entre o $\mathrm{N}$ fixado, $\mathrm{N}$ nativo do solo e $\mathrm{N}$ do fertilizante. Para a soja não nodulante, aos 76 DAS, a QNT aumentou à medida que se aumentou a dose de $\mathrm{N}$, obtendo-se a máxima acumulaçáo com 60 $m g \mathrm{~kg}^{-1} \mathrm{de} \mathrm{N}$, indicando assim, que o $\mathrm{N}$-fertilizante foi o principal responsável pelo acúmulo deste nutriente pela planta. Resultados semelhantes foram também verificados para caupi e soja por ENGLESHAM et al. (1983).

A porcentagem de nitrogênio na planta proveniente do fertilizante (\%NPPF), em ambas as espécies e nas três épocas avaliadas, na planta de feijão, aumentou com o incremento da dose de N (Figura 3a,b); no entanto, com maior intensidade nas menores doses de N. Já a quantidade de nitrogênio na planta proveniente do fertilizante (QNPPF) nas três épocas avaliadas, foi proporcional à dose de $\mathrm{N}$ aplicada (Figura 3c). Para o caupi, houve tendência 
de decréscimo na QNPPF com o aumento da dose de N (Figura 3d), acima de $15 \mathrm{mg} \mathrm{kg}^{-1}$ de N, nas épocas 23 e 40 DAS, e acima de $30 \mathrm{mg} \mathrm{kg}^{-1}$ de $\mathrm{N}$, aos 76 DAS.

A maior QNPPF foi obtida com a maior dose de $\mathrm{N}$ (60 mg kg-1), cujos valores foram de 45,58 $\mathrm{mg}^{-1 a n t a}{ }^{-1}$ de $\mathrm{N}$ para o caupi e de $67,05 \mathrm{mg}$ planta $^{-1}$ de $\mathrm{N}$ para o feijão comum, correspondendo, à participação da ordem, respectivamente, de 59,61\% e 64,08\% do N total. Resultados bem próximos aos do presente estudo foram verificados por RenNie e Kemp (1984), quando a adiçáo de $10 \mathrm{~kg} \mathrm{ha}^{-1}$ de $\mathrm{N}$ contribuiu pouco para o $\mathrm{N}$ total na planta de feijão (cvs. Kentowood e Aurora), sendo a média de \%NPPF para ambas as cultivares de 14\% em 1981 e $12,3 \%$ em 1982, no estádio $\mathrm{V}_{3}$ (40 DAS), com decréscimo depois desta fase. Os autores observaram ainda que a maior utilização do $\mathrm{N}$ ocorreu com a dose de $40 \mathrm{~kg} \mathrm{ha}^{-1}$ de N, em média, 30,3\% em 1981 e 27,4\% em 1982.

$\mathrm{O}$ aproveitamento do $\mathrm{N}$-fertilizante, pelo feijão, aos 23 DAS, decresceu de $37,8 \%$ para $19,2 \%$, respectivamente, com a aplicação da dose $2 \mathrm{mg} \mathrm{kg}^{-1}$ de $\mathrm{N}$ e $60 \mathrm{mg} \mathrm{kg}^{-1}$ de N. Já, aos 40 DAS, variou entre $61,7 \%$ e $67,1 \%$ e, aos 76 DAS, se manteve praticamente constante, com aproveitamento médio de 60,6\% (Figura 3e). Para o caupi, nas três épocas avaliadas, à medida que se elevaram as dose de $\mathrm{N}$, ocorreu um decréscimo no aproveitamento do $\mathrm{N}$ do fertilizante (Figura 3f), evidenciando redução na sua concentração na parte aérea. A maioria dos estudos demonstra que existe grande variação no aproveitamento do $\mathrm{N}$ do fertilizante pelas plantas, raramente ultrapassando 50\% do aplicado (Alfaia, 1997). No presente
FEIJÃO COMUM

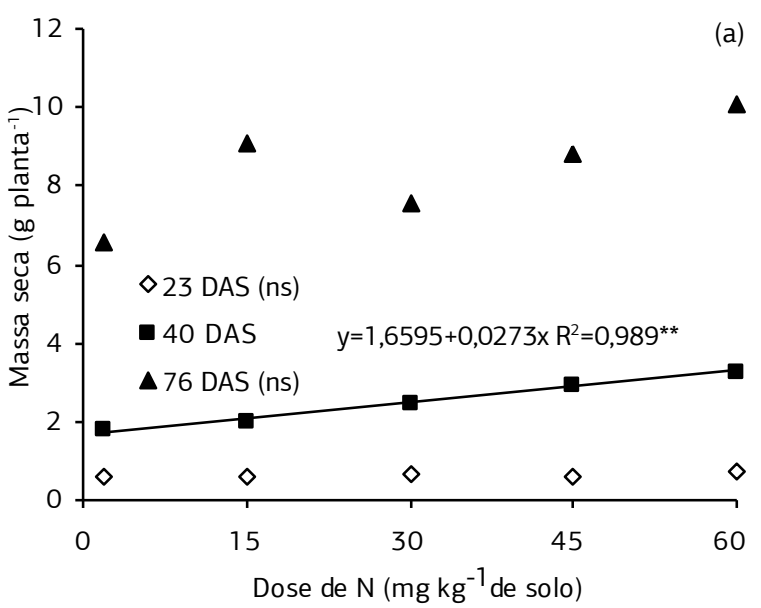

CAUPI

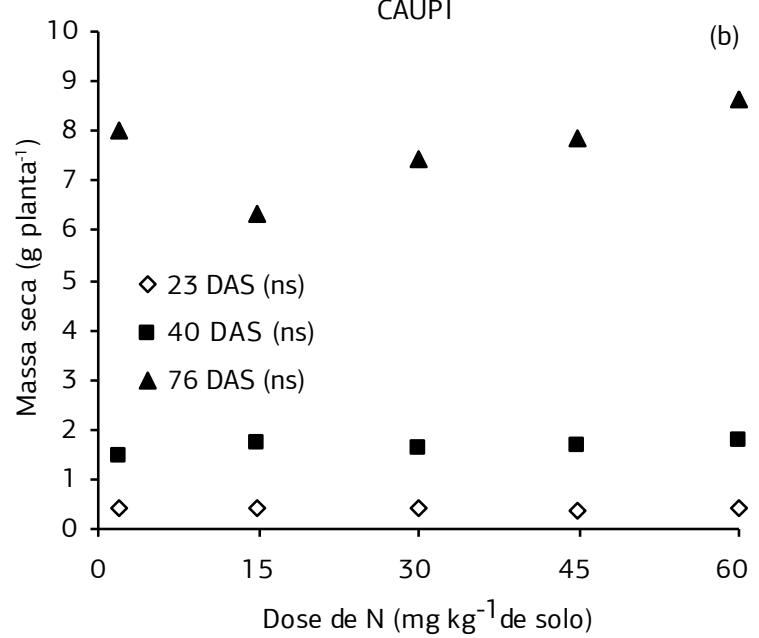

Figura 1. Produção de matéria seca de parte aérea (caule + ramos + folhas + pedúnculos e vagens) do feijão comum (a) e caupi (b), aos 23, 40 e 76 dias após a semeadura (DAS), em função de doses de N. Cada símbolo indica o valor médio de quatro repetiçóes ns: não significativo. ${ }^{* *}$ : significativo a $1 \%$ de probabilidade.
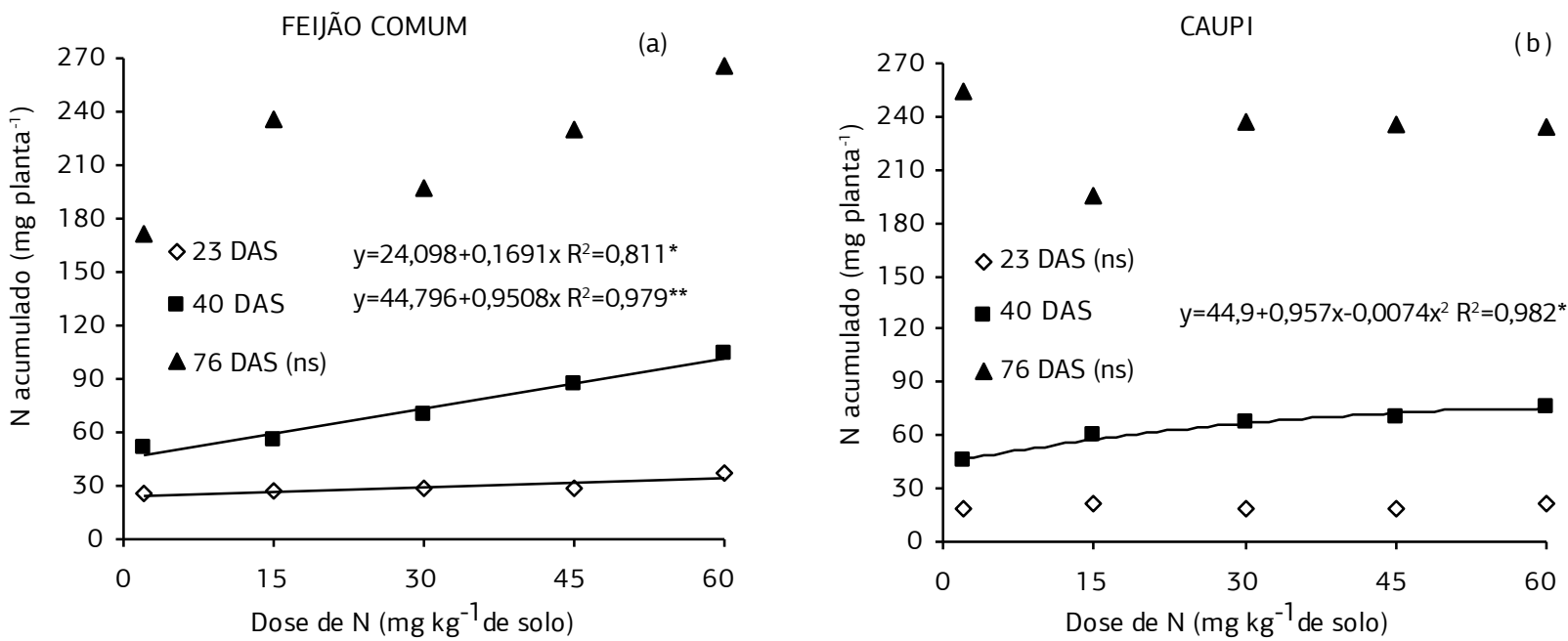

Figura 2. Quantidade de $\mathrm{N}$ total acumulada na parte aérea (caule + ramos + folhas + pedúnculos e vagens) de feijão comum (a) e caupi (b), aos 23, 40 e 76 dias após a semeadura (DAS), em função de doses de N. Cada símbolo indica o valor médio de quatro repetiçôes. ns: não significativo. ${ }^{* *},{ }^{*}$ : significativo a $1 \%$ e $5 \%$ de probabilidade respectivamente. 
estudo, o aproveitamento relativamente alto para as duas plantas fixadoras de $\mathrm{N}$, provavelmente está relacionado à condição de vaso, onde o sistema radicular permanece confinado, explorando todo volume de solo e, também, não ocorrendo perda de $\mathrm{N}$ por lixiviação, para camadas fora do alcance das raízes.
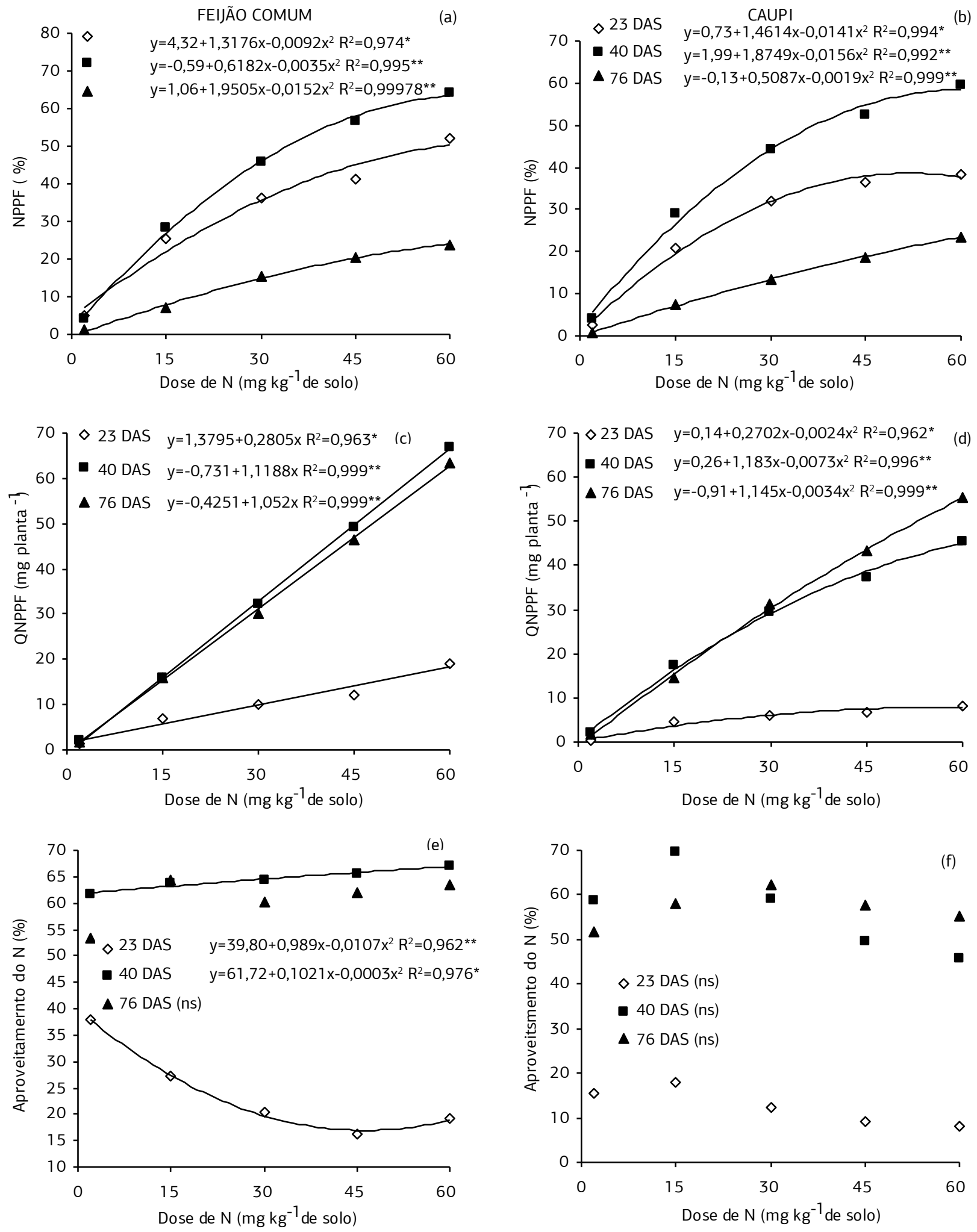

Figura 3. Porcentagem (\%NPPF) (a e b) e quantidade (QNPPF) (c e d) e aproveitamento do nitrogênio (e e f) do fertilizante pela parte aérea (caule + ramos + folhas + pedúnculos e vagens) de feijão comum e caupi, aos 23, 40 e 76 dias após a semeadura (DAS), em função de doses de N. Cada símbolo indica o valor médio de quatro repetiçóes. ns: não significativo. **,*: significativo a $1 \%$ e $5 \%$ de probabilidade respectivamente. 
A porcentagem de nitrogênio proveniente da fixação simbiótica (\%NPPFB) no feijāo (Figura 4a) e no caupi (Figura $4 \mathrm{~b}$ ) decresceu proporcionalmente ao incremento da dose de $\mathrm{N}$, demonstrando que o aumento na concentração de $\mathrm{N}$ mineral na solução do solo desfavoreceu o processo de simbiose entre a planta e o rizóbio.

$\mathrm{O}$ tratamento que recebeu a menor dose de $\mathrm{N}$ (2 mg kg-1) exibiu a maior média $\left(207,53 \mathrm{mg}^{-1}\right.$ planta $\left.^{-1}\right)$ de QNPPFB, correspondendo a $81,49 \%$ do nitrogênio total. As plantas de feijão submetidas às doses de 2 ou $15 \mathrm{mg} \mathrm{kg}^{-1}$ de $\mathrm{N}$ de solo tiveram as maiores médias de \%NPPFB, de $71,62 \%$ e $71,89 \%$ respectivamente, não diferindo entre si.

O maior valor de QNPPFB no feijão foi obtido no tratamento $15 \mathrm{mg} \mathrm{kg}^{-1}$ de $\mathrm{N}$, evidenciando que a aplicação de pequenas doses de $\mathrm{N}$ mineral no início do desenvolvimento do feijoeiro foi favorável à planta hospedeira, certamente em virtude de promover maior envio de fotossintatos ao sistema radicular e, assim, promover aumento no crescimento da raiz, aumentando os sítios de formação de nódulos e consequentemente aumento na fixação biológica de nitrogênio (Franco e Dóbereiner, 1968; Huxley, 1980; Tsai et al., 1993).

A planta de caupi submetida à dose de $2 \mathrm{mg} \mathrm{kg}^{-1}$ de $\mathrm{N}$ proporcionou maior \%NPPFB em relação aos demais tratamentos e, à medida que se elevou a concentração de $\mathrm{N}$ no vaso, decresceram as \%NPPFB. Com base nesses resultados, confirmam-se as observaçóes de outros estudos de que altas doses de $\mathrm{N}$ afetam a fixação em caupi (Miller et al., 1982; Berverly e Jarrel, 1984; Graham e Scott, 1984; Agbenin et al., 1990; Alfaia 1997). Neste contexto, Eaglesham et al. (1982) concluíram que embora as taxas de utilização do $\mathrm{N}$-fertilizante pelo caupi tenham sido baixas, de $12 \%$ e $28 \%$ com a aplicação de 25 e 100 $\mathrm{kg} \mathrm{ha}^{-1}$ de $\mathrm{N}$ respectivamente, a menor dose promoveu
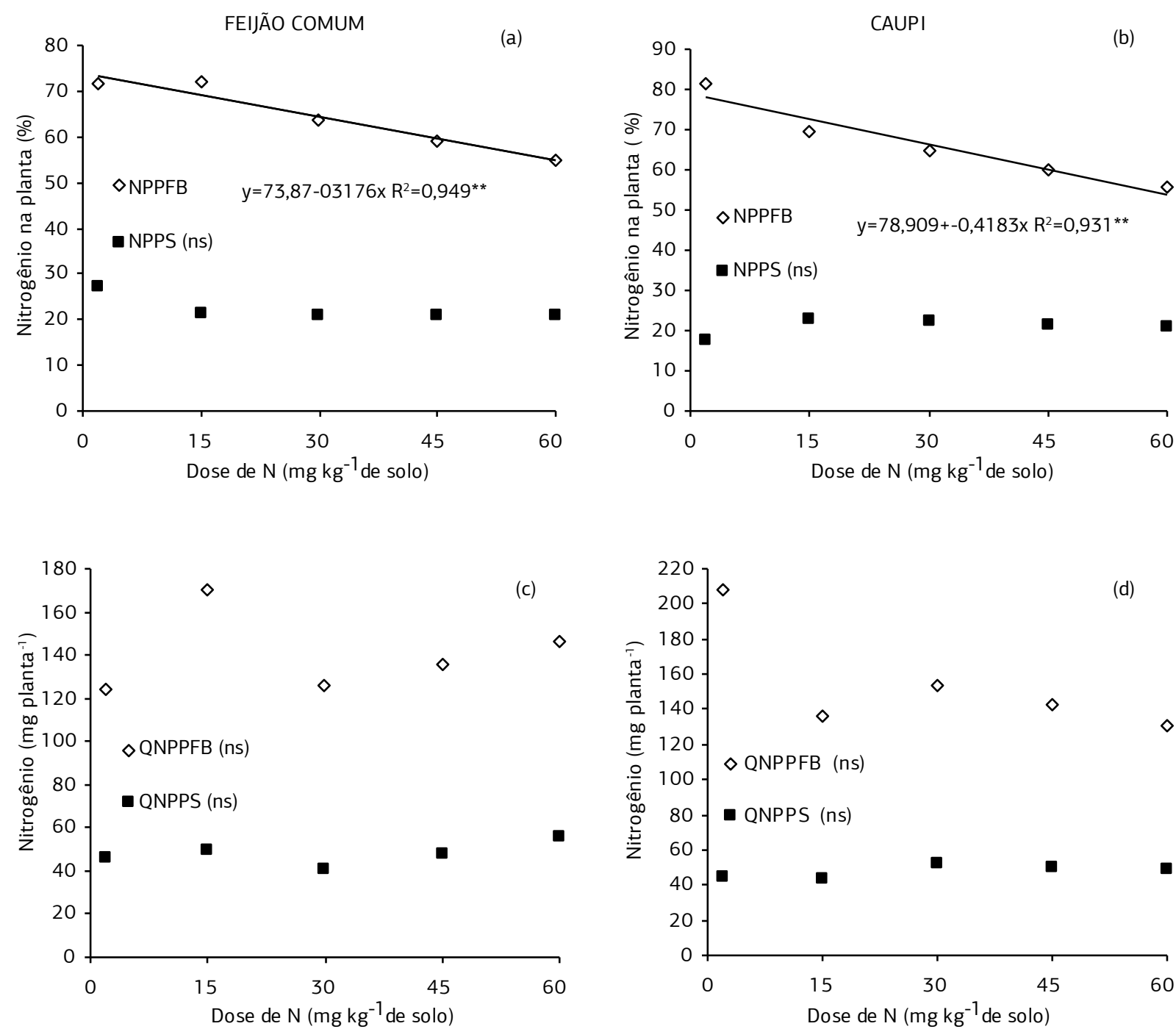

Figura 4. Porcentagem de nitrogênio na planta (caule + ramos + folhas + pedúnculos e vagens) de feijão comum (a) e caupi (b) proveniente da fixaçáo biológica (\%NPPFB) e do solo (\%NPPS) e quantidade nitrogênio na planta de feijáo comum (c) e caupi (d) proveniente da fixaçáo biológica (QNPPFB) e do solo (QNPPS), aos 76 dias após a semeadura, em funçáo de doses de N. Cada símbolo indica o valor médio de quatro repetiçóes. ns: não significativo. ${ }^{* *}$ : significativo a $1 \%$ de probabilidade. 
efeito adverso sobre o desenvolvimento dos nódulos e a maior dose de $\mathrm{N}$, proporcionou efeito adverso prolongado na formação e desenvolvimento dos nódulos.

A porcentagem (\%NPPS) (Figura 4a) e a quantidade de nitrogênio do solo (QNPNS) (Figura 4b) nas plantas de caupi e feijáo se manteve mais ou menos constantes, não sofrendo influência das doses de $\mathrm{N}$. Tal fato indica que, provavelmente, as distintas doses de $\mathrm{N}$ não influenciaram a mineralização do $\mathrm{N}$ orgânico do solo e/ou a magnitude de absorção do $\mathrm{N}$ desta fonte.

Comparando-se os valores de QNPPF (Figura 3c,d), aos 76 DAS, com os de QNPPFB QNPPS (Figura 4c,d), observa-se que, à exceção dos tratamentos que receberam 45 ou $60 \mathrm{mg} \mathrm{kg}^{-1} \mathrm{~N}$, cujos os valores foram parecidos, nos demais tratamentos a contribuição das fontes de $\mathrm{N}$ para o $\mathrm{N}$ acumulado no feijão e no caupi seguiram a ordem decrescente NPPFB > NPPS > NPPF. De maneira geral, as doses de $\mathrm{N}$ influenciaram negativamente a fixação simbiótica do $\mathrm{N}_{2}$, que variou de $55,6 \%$ a $81,5 \%$ para o caupi, e de $55,1 \%$ a $71,9 \%$ para o feijão comum. Mendes et al. (2008) relataram que sempre que a disponibilidade de $\mathrm{N}$ no solo é abundante, este é absorvido em detrimento ao $\mathrm{N}$ da fixação, enquanto o $\mathrm{N}$-fixado é a maior fonte do nutriente quando o $\mathrm{N}$ do solo torna-se limitante.

Os resultados referentes à estimativa da atividade da nitrogenase, aos 76 DAS, tanto para o feijáo como para caupi não se ajustaram significativamente aos modelos testados (Figura 5). Os valores do início até em torno da metade do ciclo do caupi e feijão (23 e 40 DAS) revelaram valores baixos, evidenciando menor atividade de fixação biológica de $\mathrm{N}$ nestas fases, comparada à fase após o florescimento. O sucesso na formação de uma simbiose funcional é dependente de muitos fatores não

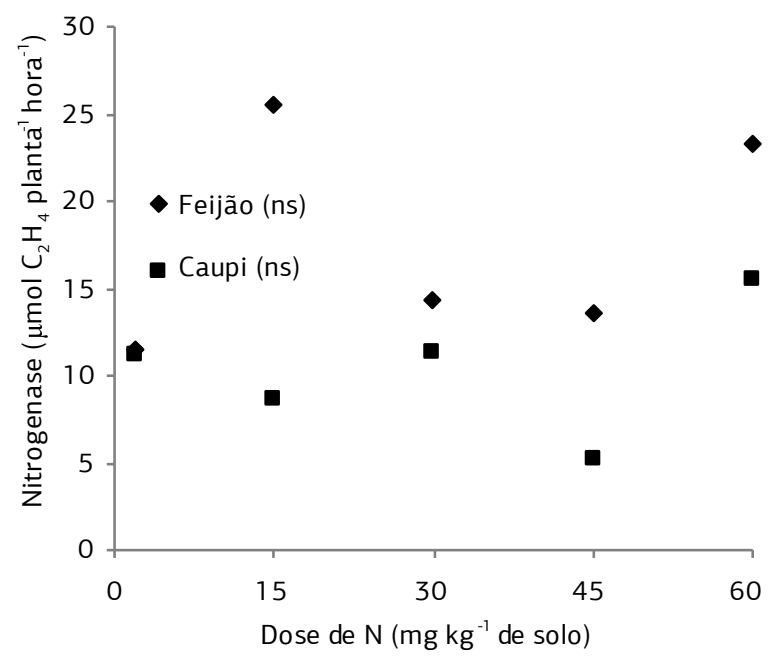

Figura 5. Atividade da redução do acetileno (ARA) nos nódulos de feijão comum e caupi, aos 76 dias após a semeadura, em função de dose de $\mathrm{N}$ e épocas de coleta. Cada símbolo indica o valor médio de quatro repetiçôes. ns: não significativo. sequenciais tais como: físicos, ambientais (umidade, temperatura, intensidade da luz), nutricionais e biológicos (Hungria et al., 1991). Além de fatores relacionados à planta (variedade) e à estirpe, bem como pela interação entre estes (SOAREs et al., 2006a,b). Assim, vários fatores influenciam o desenvolvimento vegetativo, a atividade do rizóbio e a nodulação, sendo, muitas vezes, considerados mais importantes do que a adubaçáo nitrogenada (EAglesham et al., 1983; Xavier et al., 2007).

As reduçôes no crescimento em plantas dependentes de $\mathrm{N}_{2}$ ocorrem, principalmente, em virtude da baixa disponibilidade de $\mathrm{N}$ na fase prévia ao início da fixação de $\mathrm{N}_{2}$, e podem ser diminuídas ou evitadas com a adubação de arranque no momento da semeadura. Essa prática é recomendada por vários pesquisadores (SUMMERFIELD et al., 1977; Huxley, 1980; Hungria et al., 1991; Oliveira et al., 2003), em virtude de estimular o crescimento da planta e evitar que passe por estado de carência antes do início da fixação, possibilitando boa nodulação. No presente estudo, os resultados de MSPA (Figura 1b), QNT (Figura 2b), \%NPPFB (Figura 4b) e QNPPFB (Figura 4d) no tratamento que recebeu apenas $2 \mathrm{mg} \mathrm{kg}^{-1}$ de $\mathrm{N}$ confirmam a potencialidade de que a associação do caupi com o rizóbio pode substituir totalmente a adubação nitrogenada mineral e que, havendo condiçóes de solo e da planta para a plena simbiose, é dispensável inclusive a adubação de arranque (semeadura). Neste contexto, Alfaia (1997), em condiçóes de campo, em um Latossolo Amarelo, não obteve efeito significativo da aplicação de $30 \mathrm{~kg} \mathrm{ha}^{-1}$ de $\mathrm{N}$, atribuindo a falta de resposta à FBN. Martins et al. (2003) verificaram que a inoculação com rizóbio (BR 3267) em caupi, em área de sequeiro, promoveu aumento de $35 \%$ na produtividade de grãos, equivalente à aplicação de $50 \mathrm{~kg} \mathrm{ha}^{-1}$ de N mineral. SOARES et al. (2006a) verificaram que a inoculação em campo com as estirpes UFLA 03-84 e INPA 03-11B contribuiu para o aumento no rendimento de grãos, semelhantemente ao tratamento que recebeu 70 $\mathrm{kg} \mathrm{ha}^{-1}$ de $\mathrm{N}$, sem inoculaçáo, e superior ao da estirpe BR 2001, que também foi utilizada no presente estudo.

Em feijão, busca-se substituir parcial ou totalmente a adubação nitrogenada, por meio da fixação simbiótica. No entanto, de acordo com os valores obtidos de MSPA (Figura 1a) e de QNT (Figura 2a) associados aos valores de \%NPPFB (Figura 4a) e de QNPPFB (Figura 4c) do tratamento que recebeu $15 \mathrm{mg} \mathrm{kg}^{-1}$ de $\mathrm{N}$, indicam que a combinação do feijão comum com o rizóbio necessita dessa dose de arranque para a obtenção de produtividades econômicas aceitáveis.

Vale lembrar que no presente estudo não foi mensurado as contribuiçôes das fontes $\mathrm{N}_{2}$-fixação simbiótica, $\mathrm{N}$-solo e $\mathrm{N}$-uréia para sistema radicular do feijão comum e do caupi, representando, portanto, substantiva do total de $\mathrm{N}$ recuperado ou acumulado pelas plantas. 


\section{CONCLUSÕES}

1. O incremento na dose de nitrogênio proporciona redução na fixação simbiótica de nitrogênio nas plantas de feijão comum e de caupi.

2. A fixação simbiótica de nitrogênio fornece a maior parte do $\mathrm{N}$ acumulado nas plantas de feijão e caupi, seguida, em ordem decrescente, pelo solo e uréia.

3. A fixação simbiótica de $\mathrm{N}_{2}$ em feijão-caupi submetido à inoculação pode substituir totalmente a adubação nitrogenada, inclusive a dose de arranque (semeadura).

4. O aproveitamento do $\mathrm{N}$ da uréia, aos 76 DAS, foi, em média, de $60,7 \%$ pelo feijão comum e de $57,1 \%$ pelo caupi e sua participação no $\mathrm{N}$ acumulado na planta de feijāo foi proporcional à dose aplicada.

5. A associação simbiótica em feijão comum necessita de uma dose de arranque ( $40 \mathrm{~kg} \mathrm{ha}^{-1} \mathrm{de} \mathrm{N}$ ) para a obtenção de produtividade economicamente aceitável.

6. A absorção do $\mathrm{N}$ do solo náo é influenciada pela dose de fertilizante nitrogenado.

\section{AGRADECIMENTOS}

A International Atomic Energy Agency (IAEA), pelo apoio financeiro para realização da pesquisa; à CAPES, ao CNPq e à FAPESP, pela concessão de bolsa, respectivamente, ao primeiro, segundo e terceiro autores.

\section{REFERÊNCIAS}

AGBENIN, M.W.; COYNE, D.P.; DAVIS, J.H.C.; GRAHAM, P.H.; AGBENIN, J.O.; LOMBIN, G.; OWONUBI, J.J. Effect of boron and nitrogen fertilization on cowpea nodulation, mineral nutrition and grain yield. Fertilizer Research, v.22, p.71-78, 1990.

ALFAIA, S.S. Destinos de fertilizantes nitrogenados $\left({ }^{15} \mathrm{~N}\right)$ em um Latossolo Amarelo cultivado com feijāo caupi (Vigna unguiculata L.). Acta Amazônica, v.27, p.65-72, 1997.

ALVES, B.J.R.; ZOTARELLI, L.; JANTALIA, C.P.; BODDEY, R.M.; URQUIAGA, S. Emprego de isótopos estáveis para o estudo do carbono e nitrogênio no sistema solo-planta. In: AQUINO, A.M.; ASSIS, R.L. (Org.). Processos biológicos no sistema soloplanta: Ferramentas para uma agricultura sustentável. Brasília, DF: Embrapa Informação Tecnológica, 2005. v.1, p.343-368.

ASSOCIAÇÃO NACIONAL PARA DIFUSÃO DE ADUBOS E CORRETIVOS AGRÍCOLAS -ANDA. Acidez do solo e calagem. São Paulo, 1986. 16p. (Boletim técnico 1)

BERVERLY, R.R.; JARREL, W.M. Cowpea response to N from, rate and liming application. Agronomy Journal, v.76, p.663-668, 1984.

BODDEY, R.M.; CHALK, P.M.; VICTORIA, R.L.; MATSUI, E. The ${ }^{15} \mathrm{~N}$ isotope dilution technique applied to the estimation of biological nitrogen fixation associated with Paspalum notatum cv. in the field. Soil Biology and Biochemistry, v.15, p.25-32, 1983.
BREMNER, J.M.; MULVANEY, C.S. Nitrogen total. In: PAGE, A.L.; MILLER, R.H.; KENEY, D.R. (Ed.). Methods of soil analysis: Chemical and microbiological properties. 2.ed. Madison: ASA, 1982. v.2, cap.31, p.595-624. (Agronomy; a series of monographs, 9)

CENTRO INTERNACIONAL DE AGRICULTURA TROPICAL - CIAT (Cali, Colômbia). Research constraints provisionally by CIAT. In: WOKSHOP ON ADVANCED PHASEOLUS BEANS RESEARCH NETWORK, 1990. Cali: CIAT, 1990. 30p. (Impresso)

DAY, P. R. Particle fractionation and particle-size analysis. In: BLACK, C. A.; EVANS, D. D.; WHITE, J. L. (Ed.). Methods of soil analysis. Madison: ASA, 1965. p. 545-567. (Part. I)

EAGLESHAM, A.R.J.; AYANABA, A.; RAO, V.R.; ESKEW, D.L. Mineral $\mathrm{N}$ effects on cowpea and soybean crops in a Nigerian soil. I. Development, nodulation, acetylene reduction and grain yield. Plant and Soil, v.68, p.171-181, 1982.

EAGLESHAM,A.R.J.;HASSOUNA, S.;SEEGERS, R. Fertilizer-N effects on $\mathrm{N}_{2}$ fixation by cowpea and soybean. Agronomy Journal, v.75, p.61-66, 1983.

EMPRESA BRASILEIRA DE PESQUISA AGROPECUÁRIA EMBRAPA. <http://www.embrapa.br/embrapa/imprensa/ noticias/2008/setembro/4a-semana/brs-Xquexique-primeiracultivar-de-feijao-caupi-biofortificada>. Acesso em 30 de set. 2008.

FOOD AND AGRICULTURE ORGANIZATION OF THE UNITED NATIONS - FAO. <http://faostat.fao.org/faostat/>. Dados de produção agrícola mundial. Última atualização em 2004. Acesso em 20 de jan. 2007.

FRANCO, A.A.; DÓBEREINER, J. Interferência do cálcio e nitrogênio na fixação simbiótica do $\mathrm{N}$ por duas variedades de Phaseolus vulgaris L. Pesquisa Agropecuária Brasileira, v.3, p.223-227, 1968.

FRANCO, M.C.; CASSINI, S.T.A.; OLIVEIRA, V.R.; VIEIRA, C.; TSAI, S.M. Nodulação em feijão dos conjuntos gênicos andino e mesoamericano. Pesquisa Agropecuária Brasileira, v.37, p.1145-1150, 2002.

GRAHAM, R.A.; SCOTT, T.W. Response of cowpea (Vigna unguiculata L. Walp.) to nitrogen and inoculation in Trinidad. Tropical Agriculture, v.61, p.56-58, 1984.

HARDARSON, G.; DANSO, S.K.A. Use of ${ }^{15} \mathrm{~N}$ methodology to assess biological nitrogen fixation. In: HARDARSON, G. (Ed.). Use of nuclear techniques in studies of soil-plant relationships. Vienna: IAEA, 1990. p.129-160. (Training course series, 2)

HARDY, R.W.F.; HOSTEN, R.D.; JACKSON, E.K.; BURNS, R.C. The acetylene-ethylene assay for $\mathrm{N}_{2}$-fixation: laboratory and field evaluations. Plant Physiology, v.43, p.1185-1207, 1968.

HUNGRIA, M.; VARGAS, M.A.T. Fixação biológica de nitrogênio em feijoeiro. In: HUNGRIA, M.; VARGAS, M.A.T.; ARAÚJO, R.S. Biologia dos solos dos cerrados. Planaltina, DF: EMBRAPACPAC, 1997, 524p.

HUNGRIA, M.; BARRADAS, C.A.; VALLSGROVE, R.M. Nitrogen fixation, assimilation and transport during the initial growth stage of Phaseolus vulgaris L. Journal of Experimental Botany, v.42, p.839-844, 1991. 
HUXLEY, P.A. Nitrogen nutrition of cowpea (Vigna unguiculata) IV. Uptake and distribution of a single dose of early applied nitrogen. Tropical Agriculture, v.57, p.193-202, 1980.

INSTITUTO BRASILEIRA DE GEOGRAFIA E ESTATÍSTICA - IBGE. Dados conjunturais do feijão (área, produção e rendimento) Brasil - 1986 a 2003. <http://www.cnpaf.embrapa. br/apps/socioeconomia>. Acesso em: 25 jan. 2005.

MARTÍNEZ-ROMERO, E.; SEGOVIA, L.; MERCANTE, F.M.; FRANCO, A.A.; GRAHAM, P.; PARDO, M.A. Rhizobium tropici, a novel species nodulating Phaseolus vulgaris $\mathrm{L}$. beans and Leucaena sp. trees. International Journal of Systematic Bacteriology, v.41, p.417-426, 1991.

MARTINS, L.M.; XAVIER, G.R.; RANGEL, F.W.; RIBEIRO, J.R.A.; NEVES, M.C.P.; MORGADO, L.B.; RUMJANEK, N.G. Contribution of biological nitrogen fixation to cowpea: a strategy for improving grain yield in the semi-arid region of Brazil. Biology and Fertility of Soils, v.38, p.333-339, 2003.

MENDES, I.C.; REIS JUNIOR, F.B.; HUNGRIA, M.; SOUSA, D.M.G.; CAMPO, R.J. Adubação nitrogenada suplementar tardia em soja cultivada em latossolos do Cerrado. Pesquisa Agropecuária Brasileira, v.43, p.1053-1060, 2008.

MILLER Jr., J.C.; SCOTT, J.S.; ZARY, K.W.; O'HAIR, S.K. The influence of available nitrate levels on nitrogen fixation in tree cultivars cowpea. Agronomy Journal, v.74, p.14-18, 1982.

OLIVEIRA, A.P.; SILVA, V.R.F.; ARRUDA, F.P.; NASCIMENTO, I.S.; ALVES, A.U. Rendimentos de feijão caupi em função de doses e formas de aplicação de nitrogênio. Horticultura Brasileira, v.21, p.77-80, 2003.

OLIVEIRA, I.P; DANTAS, J.P. Nutrição mineral do caupi. In: ARAUJO, J.P.; WATT, E.E. O caupi no Brasil. Brasília: ITA/ EMBRAPA, 1988. p.405-430.

OLIVEIRA, I.P.; THUNG, M.D.T. Nutrição mineral. In: ZIMMERMANN, M.J.O.; ROCHA, M. ; YAMADA, T. Cultura do feijoeiro - fatores que afetam a produtividade. Piracicaba, POTAFOS, 1988. p.175-212.

PELEGRIN, R; MERCANTE, F.M.; OTSUBO, I.M.N.; OTSUBO, A.A. Resposta da cultura do feijoeiro à adubação nitrogenada e à inoculaçáo com rizóbio. Revista Brasileira de Ciência do Solo, v.33, p.219-226, 2009.

PORTER, L.K.; O'DEEN, W.A. Apparatus for preparing nitrogen from ammonium chloride for nitrogen-15 determinations. Analytical Chemistry, v.49, p.514-516, 1977.
RENNIE, R.J.; KEMP, G.A. ${ }^{15} \mathrm{~N}$-determined time course for $\mathrm{N}_{2}$ fixation in two cultivars of field bean. Agronomy Journal, v.76, p.146-154, 1984.

RITTENBERG, D. The preparation of gas sample for massspectrometric analysis. In: WILSON, D.W. (Ed.). Preparation and measure of isotopic traces. Michigan: Ann Arbor, 1946. p.31

SAITO, S.M.T.; MATSUI, E.; SALATI, E. ${ }^{15} \mathrm{~N}_{2}$ fixation, $\mathrm{H}_{2}$ evolution and $\mathrm{C}_{2} \mathrm{H}_{2}$ reduction relationship in Phaseolus vulgaris. Physiologia Plantarum, v.49, p.37-42, 1980.

SAS INSTITUTE. The SAS-System for Windows release 6.11 (software). Cary, 2001.

SOARES, A.L.L.; PEREIRA, J.P.A.R.; FERREIRA, P.A.A.; VALE, H.M.M.; LIMA, A.S.; ANDRADE, M.J.B.; MOREIRA, F.M.S. Eficiência agronômica de rizóbios selecionados e diversidade de populações nativas nodulíferas em Perdōes (MG). I - Caupi. Revista Brasileira de Ciência do Solo, v.30, p.795-802, 2006 a.

SOARES, A.L.L.; FERREIRA, P.A.A.; PEREIRA, J.P.A.R. VALE, H.M.M.; LIMA, A.S.; ANDRADE, M.J.B.; MOREIRA, F.M.S. Eficiência agronômica de rizóbios selecionados e diversidade de populações nativas nodulíferas em Perdóes (MG). II - Feijoeiro. Revista Brasileira de Ciência do Solo, v.30, p.803-811, 2006 b.

SPRENT, J.I.; SPRENT, P. Nitrogen fixing organisms pure and applied aspects. London: Chapman and Hall, 1990, 256p.

SUMMERFIELD, R.J.; DART, P.J.; HUXLEY, P.A.; EAGLESHAM, A.R.J.; MINCHIN, F.R.; DAY, J.M. Nitrogen nutrition of cowpea (Vigna unguiculata). I. Effect of applied nitrogen and symbiotic nitrogen fixation on growth and seed yield. Experimental Agriculture, v.13, p.129-142, 1977.

TSAI, S.M.; BONETTI, R.; AGBALA, S.M.; ROSSETO, R. Minimizing the effect of mineral nitrogen on biological nitrogen fixation in common bean by increasing nutrient levels. Plant and Soil, v.152, p.131-138, 1993.

URQUIAGA, S.; BODDDEY, R.M. Theoretical considerations in the comparison of total nitrogen difference and ${ }^{15} \mathrm{~N}$ isotope dilution estimates of the contribution of nitrogen fixation to plant nutrition. Plant and Soil, v.102, p.291-294, 1987.

XAVIER, T.F.; ARAÚJO, A.S.F.; SANTOS, V.B.; CAMPOS, F.L. Ontogenia da nodulaçáo em duas cultivares de feijão-caupi. Ciência Rural, v.37, p.56-564, 2007. 